\title{
Um misantropo para todos os tempos
}

\author{
Maria João Brilhante
}

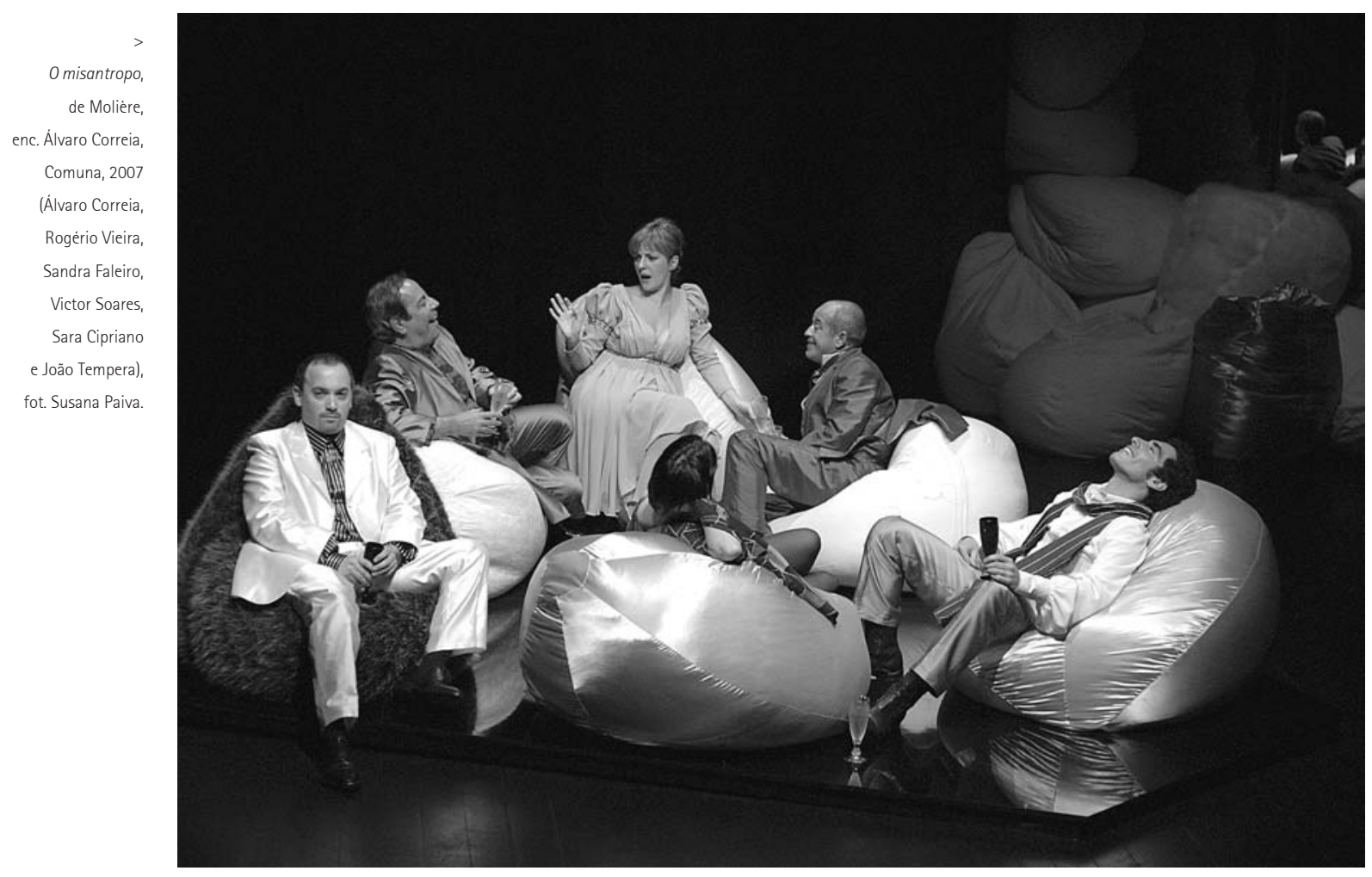

Titulo: O misantropo (The Misanthrope,1666). Autor: Molière. Tradução:Luis Miguel Cintra. Encenação:Álvaro Correia. Cenografia: Marta Silva. Figurinos: Carlos Paulo. Desenho de luz: Paulo Graça. Interpretação: Álvaro Correia, João Tempera, Miguel Sermão, Sandra faleiro, Sara Cipriano, Lucinda Loureiro, Victor Soares, Rogério Vieira. Produção: Comuna - Teatro de Pesquisa. Local e data de estreia: Teatro da Comuna, 9 de Fevereiro de 2007.

Continuamente presente nos discursos de criadores e críticos, o tópico da revisitação dos clássicos não foi na realidade sujeito a uma discussão sistemática, sobretudo no que toca à presença e função destes nos palcos nacionais. Esta questão, noutras paragens associada ao tema da liberdade criadora do encenador, ao fosso cultural entre problemáticas colocadas pelos textos clássicos e a percepção que deles os espectadores são capazes de ter em cada momento, e sobretudo a experiências de desconstrução por vezes paródica que deles se faz, costuma invocar, por cá, um sentido de missão no preenchimento da grave lacuna de conhecimento do cânone dramático, a crença legitima na dimensão humanistica do teatro de outros tempos, mas reproduz também um certo senso comum acerca da nossa quase incapacidade de "encenar os clássicos". A verdade é que, por vezes, jovens criadores não resistem a mostrar a sua leitura de um texto clássico, gesto inevitável no processo de crescimento e afirmação de diferença perante os antecessores. É óbvio que no espaço desta recensão não cabe especular sobre uma questão que implica múltiplas varáveis de apreciação (histórica, artística, ideológica, cultural...), mas talvez se possa a ela voltar noutra ocasião, quanto mais não seja para tentar perceber o que esconde e o que revela a desconstrução dos clássicos.

A dramaturgia clássica francesa só há pouco regressou do limbo ao convivio com os palcos portugueses e mais por via dos tragediógrafos que dos comediógrafos. Este Misantropo que A Comuna e Álvaro Correia nos propõem constitui, por conseguinte, uma agradável surpresa por duas razões.

A primeira diz respeito ao modo distante como lida com a barreira construida, em torno do autor e das suas comédias, por um senso comum que os considera expoente máximo de um teatro ligeiro, cómico, critico da sociedade do seu tempo, teatro próximo da corte e do poder, por vezes objecto de leitura recomendada nas escolas (ainda será?), enfim, modelo para toda a comédia posterior.

A segunda razão prende-se com a própria escolha de 0 misantropo, um texto considerado estranho, já no seu tempo, que nos faz rir com algum desconforto porque 

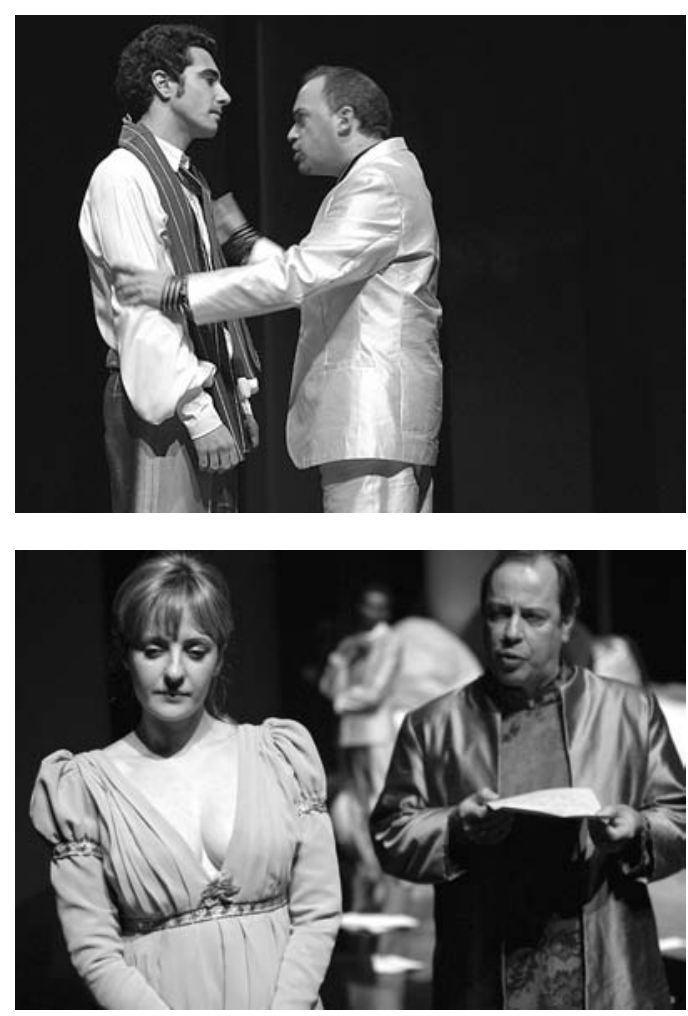

rimos de situações e de caracteres a que atribuimos, apesar do seu ridiculo, um sentido moral; um texto que provoca até alguma inquietação, talvez porque aquilo que acontece no salão de Celimena, na corte e na cidade de Paris passou, com o tempo, a parecer-nos grave e reprovável, e a converter Alceste, o misantropo ridiculo, numa espécie de justiceiro da hipocrisia.

Esta dúplice condição do texto inspirou a Álvaro Correia um espectáculo e um Alceste - que ele próprio encarna - graves, em que toda a energia foi canalizada para a enunciação de uma rede de confrontos que, ao serem suspensos, finalizam a comédia.

$\mathrm{Na}$ memória de alguns dos espectadores poderia ainda estar presente a sua criação pelo Teatro da Cornucópia, em 1973, com a qual esta produção se liga apenas por via da tradução de Luís Miguel Cintra, sobre a qual foi feito algum trabalho dramatúrgico.

Do espectáculo, há que dizer, antes de mais, que optou por não recriar o tempo e o espaço dos salões do século XVII francês, mas que também não transpôs a acção totalmente para a actualidade: a língua que as personagens falam remete-nos para tempos passados. Objectos em cena e figurinos sugeriam um interior moderno (poufs, espelhos, mesa com bebidas e aparelhagem sonora), estilizado, um

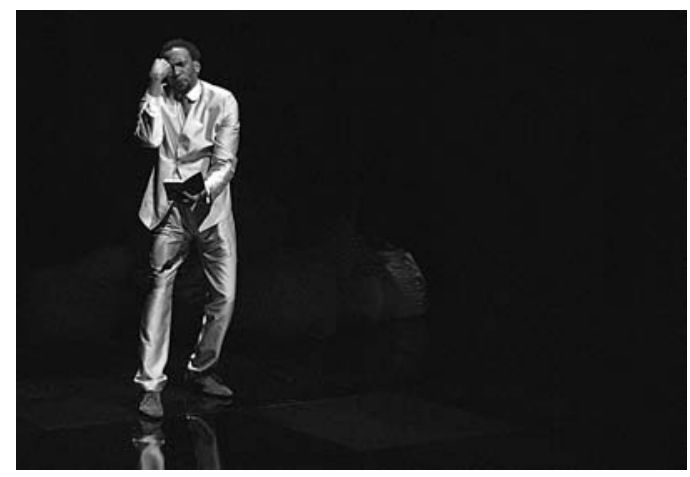

salão de quem regularmente recebe em casa, espaço visitado por pessoas que se apresentam com algum requinte, que cuidam das suas maneiras. Poderia referir neste ponto que nem todos os figurinos favoreciam os actores que os envergavam, no entanto a sua leitura não era confusa ou desligada do sentido geral da cena, dependendo, portanto, o meu comentário de uma mera questão de gosto. Creio, mesmo, ser possivel reconhecer os sinais de uma caracterização das personagens onde factores como a idade, o estatuto social, e os traços psicológicos que no texto as distinguem estão presentes (a austera, mas insinuante Arsinoê - por Lucinda Loureiro - distingue-se pelo seu trajar mais reservado).

0 espaço cénico foi explorado de forma a deixar claras as oposições fundamentais entre o salão de Celimena por Sandra Faleiro - onde a acção decorre, o exterior (a corte e a cidade) de onde chegam visitantes e rumores e o interior da casa a que alguns têm acesso. A dinâmica da acção, totalmente assente na continuidade das entradas e saídas de personagens, pode colocar alguns problemas à encenação, já que implica atenuar ou tornar menos evidente e mais económica essa continuidade, de forma a não quebrar, com tempos mortos, a energia contida e transportada pela troca de palavras entre os actores de
Omisantropo,

de Molière, enc. Álvaro Correia, Comuna, 2007 (João Tempera e Álvaro Correia), fot. Susana Paiva.

0 misantropo, de Molière, enc. Álvaro Correia, Comuna, 2007 (Sandra Faleiro e Rogério Vieira), fot. Susana Paiva. 0 misantropo, de Molière, enc. Álvaro Correia, Comuna, 2007 (Miguel Sermão), fot. Susana Paiva. 


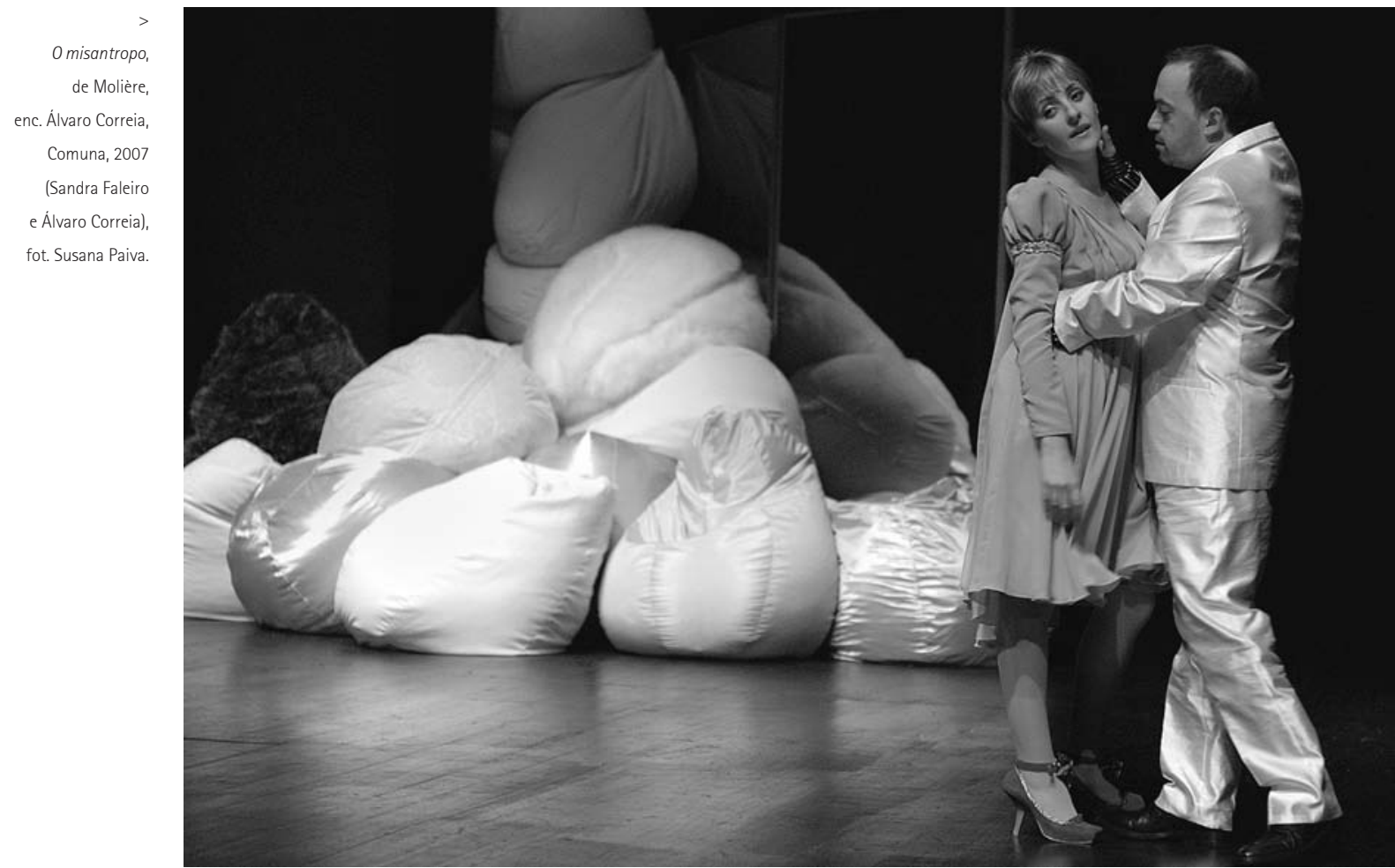

cena em cena. Tanto mais que o tema fulcral da peça é justamente a demasiada ligeireza com que se aceitam declarações de amizade e se acolhem em casa pessoas que mal conhecemos.

Embora a zona mais despida do palco parecesse, por vezes demasiado despida, a encenação mostrou estar mais interessada em destacar os actores e os seus confrontos verbais do que em disfarçar, sob um realismo de pacotilha, as dificuldades colocadas por uma acção que se constrói sobre uma quase ausência de intriga (se tal podemos chamar ao amor extravagante de Alceste por Celimena). Daí que a criação de um palco (para Celimena, mas não só) dentro do palco tenha dado origem a alguns dos melhores momentos do espectáculo, como foi o caso da violenta cena de maledicência que mostra Celimena em todo o seu esplendor. E se algumas "travessias" pelo salão nem sempre foram bem resolvidas pelos actores ou se alguns deles pareciam pouco confortáveis sentados nos poufs ou dentro das suas toilettes (a excepção parecia ser Filinto - por João Tempera -, trajado de modo menos formal) a verdade é que o espectáculo no seu todo irradiava um tónus absolutamente notável.

Creio, pois, que as raras opções de desigual eficácia relativas ao espaço e sua exploração não puseram em risco a proposta fulcral da encenação: fazer-nos entender o problema insolúvel que o Misantropo encerra e que excede a função de retratar uma "sociedade de corte", tal como a estudou Norbert Elias, complexa nas permanentes negociações pelas quais se vai submetendo ao desígnio do poder absoluto do rei. Ontem como hoje, integrar o círculo dos poderosos representava ceder a uma civilidade pouco compatível com a sinceridade.

Foi esse o aspecto que conduziu a minha percepção e que me pareceu ligar o trabalho dos actores. Julguei vislumbrar nesse investimento na energia dos actores em cena uma decisão do encenador e dos próprios actores que corresponde a um particular modo de ler o texto e de o transmitir, buscando através dessa energia conjugar o ritmo do discurso que vem de outra época com a vitalidade de uma enunciação que os corpos dos actores imprimem a esse discurso. Estar contra não constitui, na acção, posição exclusiva de Alceste, por isso, o actor soube dosear a sua "presença" em cada cena, para permitir que se iluminassem outros contrastes, outras confrontações (como a que ocorre entre Celimena e Arsinoê).

A própria paixão de Alceste por Celimena, apresentada no texto como inexplicável, adquire aqui uma tonalidade sombria, porque Sandra Faleiro propõe-se retirar à personagem a leviandade da coquette, para Ihe atribuir uma desdenhosa sobranceria, senão mesmo alguma crueldade. Mas só o percebemos porque as palavras que dizem os sentimentos e afectos desencontrados foram animadas por uma vigorosa enunciação e postas em situação de desafio e confronto.

Foi óbvio o empenho colocado na clareza dessa enunciação, tanto mais dificil de atingir quanto o texto em tradução (apresentando, sem ser em verso, alguma rima interna) se desvia do português corrente, da mesma forma que foi motivo de grande prazer para o espectador receber esse texto tonificado pelos actores. Todos sem excepção se excederam no jogo, tão caracterizador do teatro clássico francês, que consiste em manter inquebrada a cadeia da argumentação. Sem desfalecimentos, como se espera de atletas em boa forma sobre os ombros dos quais assenta o espectáculo.

Aos actores e a Álvaro Correia se deve o facto de, em momento algum, o espectador ter sido levado a distanciarse da troca verbal, do confronto de posições, da exposição de antagonismos. Só a cena final da revelação das cartas de Celimena e da sua irremediável hipocrisia veio suspender a energia que alimentou o desafio colocado, por certo, pelo encenador e actores a si próprios: dar de novo vida às palavras de Molière, fazer-nos ouvi-las e ao que nelas somos ainda capazes de entender. 